Tropical Journal of Pharmaceutical Research May 2016; 15 (5): 1109-1111

ISSN: $1596-5996$ (print); 1596-9827 (electronic)

(C) Pharmacotherapy Group, Faculty of Pharmacy, University of Benin, Benin City, 300001 Nigeria.

All rights reserved.

Available online at http://www.tjpr.org

http://dx.doi.org/10.4314/tjpr.v15i5.29

Case Report

\title{
Suppression of HIV-1 viral load after multiple changes in high active antiretroviral therapy: A case report
}

\author{
lone Takaki ${ }^{1}$, José Scoparo', Márcia A Wingeter², Cesar Helbel², Ricardo A \\ Spironello ${ }^{3}$ and Roberto KN Cuman ${ }^{3 *}$ \\ ${ }^{1}$ Department of Clinical Analysis, ${ }^{2}$ Department of Medicine, ${ }^{3}$ Department of Pharmacology and Therapeutics, State University of
} Maringá, Paraná, Brazil

*For correspondence: Email: rkncuman1@gmail.com;Tel:+55 4430114867

Received: 17 December 2015

Revised accepted: 11 April 2016

\begin{abstract}
High active antiretroviral therapy (HAART) can reduce plasma viremia to levels below the limit of detection, leading to adequate immune recovery and clinical stability in most HIV-1-infected patients. However, the virus persists in reservoirs, and free virions can be found in the plasma. We report here the case of an HIV-infected patient diagnosed in 1999, who exhibited good adherence to medication and HAART efficacy after multiple protocol changes. In this study, we describe the clinical features, chronological changes in HIV viral load and CD4+ T-cell count, and treatment outcomes of multiple combinations of antiretrovirals (ARV). The patient presented cycles of viral load during treatment ranging from undetectable, low, and intermediate HIV-1 RNA levels, to levels above the limits of quantification. A therapeutic regimen intensified with raltegravir (RAL) promoted constant depletion of HIV viral load and an increase in CD4+ T-cells. The report shows that enhanced HAART efficacy using RAL can reduce HIV viral load.
\end{abstract}

Keywords: HAART, HIV, Viral load, Antiretroviral therapy, Raltegravir

Tropical Journal of Pharmaceutical Research is indexed by Science Citation Index (SciSearch), Scopus, International Pharmaceutical Abstract, Chemical Abstracts, Embase, Index Copernicus, EBSCO, African Index Medicus, JournalSeek, Journal Citation Reports/Science Edition, Directory of Open Access Journals (DOAJ), African Journal Online, Bioline International, Open-J-Gate and Pharmacy Abstracts

\section{INTRODUCTION}

High active antiretroviral therapy (HAART) has been reported to be efficacious in hastening immunological recovery and symptomatic improvement after antiretroviral therapy (ART). Indeed, an overall good immunological response is observed, with higher CD4+ T-cell counts, temporally and quantitatively. Although ART efficacy controls viremia, many factors and events may necessitate a change in therapy, such as drug toxicity, viral resistance and mutation, treatment adherence, cost, and medical support $[1,2]$.
In spite of significant HIV-related morbidity and mortality, HAART effectively suppresses, but does not eradicate, HIV-1 infection [1]. Low but persistent HIV-1 RNA levels can still be detected in plasma and cellular reservoirs [3,4] even after several years of suppressive HAART, and cessation of treatment invariably results in the resumption of viral replication.

In addition to the persistence of long-lived, latently infected cells, low-level viral replication has been proposed as a mechanism that maintains HIV-1 during HAART. If complete viral replication cycles persist, despite suppressive ART, this would lead to a recurrence of cellular 
infection and a constant replenishment of the viral reservoir $[5,6]$.

\section{CASE REPORT}

In this case report, we describe the clinical features, chronological changes in HIV viral load and CD4+ T-cell count, and treatment outcomes associated with multiple combinations of ARV in a 46-year-old man. Data collected since 1999, the date of diagnosis, were obtained from medical records in Public Specialities Clinic. The patient received the diagnosis of HIV infection on April 1999 with subsequent medical follow-ups at an average frequency of three times per year for sixteen years. The initial physical examination was normal without any sign of chronic disease, opportunistic infection, or AIDS-defining complications.

The patient began HAART in June 1999 at which time his plasma HIV-1 RNA level was 200,000 copies $/ \mathrm{mL}$. The initial ART regimen prescribed included didadosine (DDI) + stavudine (d4T), and a good therapeutic response was observed, including full suppression of HIV plasma viremia and a CD4+ T-cell count $>500$ cells $/ \mu \mathrm{L}$.

During 16 years of treatment from 1999 to 2015 , virological and immunological responses to various combinations of $A R V$ were monitored, and multiple changes were made to the HAART regimen due to increases in HIV viral load, resistance to $A R V$, and the presence of adverse drug reactions (ADR) (Table 1$)$.

In February 2006, when the patient's plasma HIV RNA level was 183,000 copies/mL, genotypic HIV-resistance test showed resistance-conferring mutations to nucleoside reverse transcriptase inhibitor drugs, but not to non-nucleoside reverse transcriptase inhibitor or protease inhibitor (PI) drugs. Another genotypic HIV-resistance test performed in December 2008 showed no drug resistance mutations to $A R V$.

During treatment, the patient presented typical signs of ADR: lipodystrophy syndrome, nausea and vomiting, headache, dizziness, tremors, lower limb arthalgia, myalgia, rashes on the limbs, painful nodular erythema, arthritis, and nodules with suppuration of varying degrees of intensity and duration.

Despite these signs of ADR, five years of an HAART drug regimen intensified with raltegravir (RAL) promoted a persistent depletion of the HIV viral load and increase in the CD4+ T-cell count.

\section{DISCUSSION}

A major advance in HIV disease treatment occurred with the introduction of HAART, which is sufficiently potent to cause complete and prolonged cessation of viral replication to allow reconstitution of the immune system $[5,6]$. Despite this progress, only 40 to $50 \%$ of patients in clinical practice are able to achieve maximal and durable suppression of the HIV plasma viral load, and this outcome is a strong predictor of disease control [6].

In contrast to most chronic conditions, successful treatment of HIV infection requires nearly perfect adherence to the treatment regimen to reduce viral load and prevent the emergence of drugresistant variants, which reduce future treatment options and can be fatal [7-9].

Many studies have suggested that even HAART is not effective for completely eliminating HIV-

Table 1: Immunological and virological responses to HAART

\begin{tabular}{|c|c|c|c|}
\hline \multirow[b]{2}{*}{ Regimen (duration of treatment) } & \multirow[b]{2}{*}{ CD4+ (cells/ $\mu \mathrm{L})$} & \multicolumn{2}{|c|}{ HIV viral load } \\
\hline & & Copies/mL $\left(\times 10^{3}\right)$ & $\log _{10}$ \\
\hline $\mathrm{d} 4 \mathrm{~T}+\mathrm{DDI}$ (37 months) & $704 \pm 76(2)$ & $0.70 \pm 0.43(2)$ & 2.8 \\
\hline AZT + DDI (20 months) & $469 \pm 38(5)$ & $13.03 \pm 16.89(5)$ & 3.814 \\
\hline $\mathrm{AZT}+3 \mathrm{TC}+\mathrm{ATV}(27$ months $)$ & $578 \pm 129(2)$ & $36.92 \pm 81.66(2)$ & 3.132 \\
\hline $3 T C+L P V / r+T D F(5$ months $)$ & $369(1)$ & $183.00(1)$ & 5.26 \\
\hline $3 T C+E F Z+L P V / r+T D F+T 20$ (18 months) & $251 \pm 37(3)$ & $112.21 \pm 91.33(3)$ & 4.755 \\
\hline$A Z T+3 T C+L P V / r+T D F(3$ months) & $215(1)$ & $415.64(1)$ & 5.619 \\
\hline$A Z T+3 T C+T D F+R T V+F P V(4$ months $)$ & $119(1)$ & $>500.00(1)$ & 5.700 \\
\hline$A Z T+3 T C+T D F$ (3 months) & $222(1)$ & $308.14(1)$ & 5.489 \\
\hline$A Z T+3 T C+L P V / r+T D F+S Q V(7$ months $)$ & $129(1)$ & $258.81 \pm 87.87(2)$ & 5.398 \\
\hline$A Z T+3 T C+D R V+R T V+R A L 48$ months) & $281 \pm 39(11)$ & $145.65 \pm 242.81(12)$ & 4.677 \\
\hline$A Z T+3 T C+$ DRV + RTV + RAL 12 months) & $457 \pm 73(2)$ & $<0.50(2)$ & 1.7 \\
\hline
\end{tabular}


infected cells, and this could result in viral spreading via privileged anatomic compartments, including various cell populations or tissues[4]. Thus, undetectable viral loads and CD4+ T-cell count values $>400$ cells $/ \mu \mathrm{L}$, as observed in our patient, indicate the high efficacy of ART. Viral load fluctuation can lead to an increase of HIV viral load, which can occur as "blips," defined as measurable plasma viral loads $(50-1000$ copies $/ \mathrm{mL}$ ) that are immediately preceded and followed by viral loads below the detection limit [4,5], which was observed in our patient. The identification and characterization of HIV-1 cellular reservoir(s) in effectively treated patients (HIV-1 RNA below the limits of quantification) is a high priority, and we suggest that this would be an important first step towards the development of a strategy for virus eradication.

RAL belongs to the class of HIV integrase inhibitors, which target a crucial process in the life cycle of HIV. HIV-1 integrase catalyzes the insertion of the viral DNA into the genome of the host cell [9], both in circulating cells and cell reservoirs. Therefore, intensification of the drug regimen with RAL or other drugs could increase the activity of ART and enhance the inhibition of residual viral replication [10].

\section{CONCLUSION}

Administration of the ART regimen, AZT + 3TC + DRV + RTV + RAL, for 5 years suppressed HIV viral load to undetectable levels, suggesting that intensified therapy with RAL promotes persistent reduction of viremia.

\section{CONFLICT OF INTEREST}

No conflict of interest associated with this work.

\section{CONTRIBUTION OF AUTHORS}

We declare that this work was done by the authors named in this article and all liabilities pertaining to claims relating to the content of this article will be borne by the authors.

\section{REFERENCES}

1. Palella FJ, Delaney KM, Moorman AC, Loveless MO, Fuhrer J, Satten GA, Aschman DJ, Holmberg $S D$. Declining morbidity and mortality among patients with advanced human immunodeficiency virus infections. HIV outpatient study investigators. N Engl J Med 1998; 338(13): 853-860.

2. Richman $D D$, Margolis DM, Delaney M, Greene WC, Hazuda D, Pomerantz RJ. The challenge of finding a cure for HIV infection. Sci 2009; 323: 1304-1307.

3. Khan MA. Blips and its clinical relevance in HIV patients on treatment. Int $J$ Collaborative Res Intern Med Publ Health 2012; 4(6): 934-955.

4. Shen $L$, Siliciano RF. Viral reservoirs, residual viremia, and the potential of highly active antiretroviral therapy to eradicate HIV infection. J Allergy Clin Immunol 2008; 122(1): 22-28.

5. Jones LE, Perelson AS. Transient viremia, plasma viral load, and reservoir replenishment in HIV-infected patients on antiretroviral therapy. J Acquir Immune Defic Syndr 2007; 45(5): 483-493.

6. Lewin SR, Rouzioux C. HIV cure and eradication: how will we get from the laboratory to effective clinical trials? AIDS 2011; 25: 885-897.

7. Lucas GM, Chaisson RE, Moore RD. Highly active antiretroviral therapy in a large urban clinic: risk factors for virologic failures an adverse drug reactions. Ann Intern Med 1999; 131(2): 81-87.

8. Chesney M. Adherence to HAART regimens. AIDS Patient Care and STDs 2003; 17(4): 169-177.

9. Vallejo A, Gutierrez C, Hernandez-Novoa B, Diaz $L$, Madrid $N$, Abad-Fernandez $M$, et al. The effect of intensification with raltegravir on the HIV-1 reservoir of latently infected memory CD4 $T$ cells in suppressed patients. AIDS 2012; 26(15): 1885-1894.

10. Massanella M, Martinez-Picado J, Blanco J. Attacking the HIV reservoir from the Immune and Viral Perspective. Curr HIVIAIDS Rep 2013; 10: 33-41. 